Journal of Social Sciences 3 (4): 197-201, 2007

ISSN 1549-3652

(C) 2007 Science Publications

\title{
Does Subjective Class Predict the Causal Attribution for Poverty?
}

\author{
Ramzi N. Nasser \\ Notre Dame University POBOX 72 Zouk Mosbeh, Lebanon
}

\begin{abstract}
This study investigated the attributions for poverty among secondary school and university students in relation to socio-economic. The questionnaire was adapted from Feagin's ${ }^{[1]}$ and Abouchedid \& Nasser ${ }^{[2]}$, and included 15 -item poverty questionnaire. It was administered to a sample $(n=242)$ of secondary school and university students from public and private schools and universities in Lebanon. Findings showed that Lebanese youth were more inclined to attribute poverty to structural factors. Socioeconomic variable of parents' education was the only significant predictors for the causal attribution for poverty. Research in this area should extend to relate stereotypes and various socio-economic attitudes as liberalism or conservatism and their relation to attribution for poverty.
\end{abstract}

Key words: poverty attributions,

\section{INTRODUCTION}

Social research based on Heider' ${ }^{[3]}$ attribution theory can be generalized to discern four attributions for poverty, these being individualist, structuralist, fatalist $^{[1,4]}$, and cultural ${ }^{[5,6]}$. Heider ${ }^{[3]}$ attribution theory discerned between internal and external attribution types. Internal attributions for poverty tend to be individualistic that place blame and responsibility on the individual ${ }^{[4,6,7]}$ i.e. the poor. Internal attributions are seen to be causes of poverty made by individual lack of ability, work ethic (lack of), self-motivation (lack of)or laziness. External attributions for poverty according to Feagin $^{[1]}$, are classified under three main schemes. A structural attribution which people externalize responsibility for their own socio-economic state by placing blame on macro-forces as government, public or private institutions ${ }^{[8]}$, fatalistic attributions as bad luck or destiny ${ }^{[1]}$ and cultural factors ${ }^{[5]}$ as the social system, confessions or ethnicity, Normative and empirical type of studies have used a number of variables that are thought to impact attributions. For instance, some studies, examined the effects of life experiences of groups, distinguished by race, class, gender, age, education, religion, and income ${ }^{[10,13]}$, political affiliation, dominant ideology $\mathrm{y}^{[8,9,10,11,12]}$, political and institutional behavior ${ }^{[12,14]}$, and cognitive biases among different groups ${ }^{[15,16]}$. In this study, subjective socio-economic class level will be used to understand how youth attribute poverty.

Cross-Cultural Studies: Cross-cultural studies have shown mixed attribution results among people from different cultures. Carr and MacLachlan ${ }^{[16]}$ found that Malawian students held more individualistic (blame the victim) attributions for poverty than did their Australian counterparts, who favored structural explanations. One explanation to this finding is that individuals who tend to be distant from the state of poverty explain the causes for poverty among the poor,to a lack of ability or lack of effort whereas, "actors" i.e. persons directly involved who are poor themselves are more likely to externalize blame on the system. This finding is consonant with the theory of cultural variation and causal attribution presented by Hine and Montiel ${ }^{[17]}$, who argue that individuals outside the Western hemisphere will tend to attribute poverty to external factors because of a general support for the poor and grievance against societal inequities and structural deficiencies. Hine and Montiel ${ }^{[17]}$ found that structuralist attributions were higher in the Canadian sample among their Filipino counterparts. With a robust social base and a strong public services in terms of health, education, and social welfare system in shaping the sociopolitical landscape among Australians and Canadians impacts the way individuals make attributions for poverty. US samples on the other hand, show that attribution for poverty explained in individualistic terms ${ }^{[1,4,6,9]}$, reflecting the strength of a dominant individualistic ideology ${ }^{[18]}$. In a more recent study by Cozzarelli, Wilkinson \& Tagler $^{[19]}$ however, underlined change in American attitudes towards the poor based on cognitions in making the attributions. Other international studies have yielded mixed results. For instance, early studies like Feather's ${ }^{[20]}$, replicated Feagin's ${ }^{[1]}$ and found that Australians were less likely 
to attribute poverty to individualistic causes than Americans. Similarly, studies conducted outside the Western hemisphere, have shown consistent structural attribution and a lower support for an individualist attribution for poverty.

Poverty attitudes in Turkey ${ }^{[8]}$, Lebanon ${ }^{[2,21,22]}$, $\operatorname{Iran}^{[23]}$, India ${ }^{[22,24]}$, South Africa ${ }^{[21]}$ and Singaporean Chinese ${ }^{[25,26]}$ tended to provide a structuralist explanation. Turks, Lebanese, Indian, Singaporean Chinese, as Eastern societies have a predominant collective behavioral structure ${ }^{[27]}$ and may tend to deflect responsibility from the group to a more powerful and controlling externalities

Class and Attribution For Poverty: Causal attribution for poverty has also been correlated with social class ${ }^{[12]}$ and race ${ }^{[28]}$. It has been suggested, for instance, that highly educated white Americans tend to perceive causal attributions (blame the poor for their poverty) more frequently than less educated Afro-Americans ${ }^{[4]}$. Hunt's ${ }^{[9]}$ findings showed that Latinos in the US were more likely to ascribe individualistic attributions for poverty than Whites. Hunt suggested since Latino sample were from middle-class group_- seeing themselves moving up the socioeconomic ladder- feel that they gain the most from the system and thus, make attributions for poverty by blaming the poor.

The relation between class status and perceptions of poverty operate in two different ways. The more affluent persons may blame poverty on the poor, to a lack of initiative, inadequate education, or indifference (negative individualistic attributions). The second perspective gives a structural explanation for poverty and places blame on governments' inability to provide the support to its constituents. We attempted to see how attitudes among high, middle, or low class individuals predict the causal attributions for poverty.

\section{METHOD}

Participants: A random sample of 242 Lebanese high school students were opportunistically selected, these students were taking the entrance exam to enroll into a private university. The researcher, informed students of the project and then gave the attribution for poverty questionnaire. The students were told that all results would be kept confidential. The reason of choosing entering university students, is that they represent the different social class sphere of the nation so as to replicate the broad class and ideological positions of society

Questionnaire and Measures: A questionnaire consisted of two sections. The first section recorded sociodemographic information: age, gender, religion, ethnicity, and educational level of parents' (fathers' and mothers' separately), self-perceived social class, parents' occupational status and income. The second section of the questionnaire contained the poverty items; these were similar to, but not a replication of Feagin's ${ }^{[1,4]}$ instrument, previously run on three different samples ${ }^{[21,22]}$. Factor analysis run by Nasser, Abouchedid \& Khashan [21] showed three preconceptualized dimensions being structuralist, individualist and fatalist. Each of the dimensions had five items, the items are presented in appendix A. The items within each of the three dimensions constituted the Attribution for Poverty Scale.

The measures of class were adapted from Kluegel, Singleton \& Starnes ${ }^{[29]}$ subjective estimates of class, being income, and educational level. Jackman and Jackman $^{[30]}$ as early as 1973 referred to subjective class as a measure of perceptions of class hierarchy. Duncan $^{[31]}$ composed subjective class of self-reported education, occupation and total family income ${ }^{[31]}$. In this study five measures of socioeconomic status; were reported by students; the educational level of parents, father and mother: "high," "middle" and "low." Social class was self-rated; "high," "middle" and "low," and parents' income, made up of a six point, scale and recoded into three-point scale; high, middle, and low. The occupation were measured through a six levels. Level 1= "Retired, unemployed and clergymen," 2= "Employees in the farming, or industrial organizations and farmers," $3=$ "Employee (technician)," 4="Professional employee (Accountant or Teacher)," $5=$ "Trade and small scale industry," and $6=$ "Own business and white collar profession." Occupational levels were collapsed in the following manner: 1 and 2 as "low," 3 and 4 as "middle" and 5 and 6 as "high" occupational status. Students also entered their parent's income, and this was recoded into three-income levels lower one-third group, middle one third and top one third group. The educational level of parents was measured by a three level classification, "high" (University Education), "middle" (High School Degree, technical or vocational - certificate programs) and "low" (Elementary Education or no Education). Thus, we defined class as an aggregate of multi-dimensional subjective measure comprising of the subjective mothers' education, fathers' education, income, class level estimates, and occupation. By adding educational level of mother and father, their own perception of social class, income and occupational status and dividing by five (i.e., average score) a one subjective class measure was identified; (i) High Class; (ii) Middle Class; (iii) Poor. 


\section{RESULTS}

The first analysis provided a descriptive analysis of the data. Table 1 reports the means of each of the dimensions (The higher the mean value the lower the attribution). The structuralist attribution were rated the highest among the middle class students. Middle and low class students had the highest means i.e., the lowest causal attributions for poverty.

Table 1: The mean level of the three pre-established poverty attributions

\begin{tabular}{|c|c|c|c|c|}
\hline & & $\mathrm{F}$ & I & $\mathrm{S}$ \\
\hline \multirow[t]{3}{*}{ High Class } & Mean & 3.32 & 2.89 & 2.02 \\
\hline & $\mathrm{N}$ & 58 & 59 & 61 \\
\hline & $\begin{array}{l}\text { Std. } \\
\text { Deviation }\end{array}$ & 0.82 & 0.80 & 0.82 \\
\hline \multirow[t]{3}{*}{ Middle Class } & Mean & 3.34 & 2.78 & 2.19 \\
\hline & $\mathrm{N}$ & 154 & 151 & 157 \\
\hline & $\begin{array}{l}\text { Std. } \\
\text { Deviation }\end{array}$ & 0.84 & 0.79 & 0.79 \\
\hline \multirow[t]{3}{*}{ Low Class } & Mean & 3.44 & 3.07 & 2.17 \\
\hline & $\mathrm{N}$ & 23 & 23 & 24 \\
\hline & $\begin{array}{l}\text { Std. } \\
\text { Deviation }\end{array}$ & 1.02 & 0.94 & 0.85 \\
\hline \multirow[t]{3}{*}{ Total } & Mean & 3.34 & 2.83 & 2.13 \\
\hline & $\mathrm{N}$ & 235 & 233 & 242 \\
\hline & $\begin{array}{l}\text { Std. } \\
\text { Deviation }\end{array}$ & 0.85 & 0.81 & 0.81 \\
\hline
\end{tabular}

$\mathrm{F}=$ Fatalistic

I=Individualistic

$\mathrm{S}=$ Structuralistic

The regression analysis was performed first by considering each dimension of the poverty scale of fatalistic, individualistic, and structuralistic and ran a separate regression analysis by using the aggregated estimate of class. Subjective class did not predict any of the poverty attribution dimensions. Table 2 reports the unstandardized regression coefficients.

Table 2: Regression Coefficients and t-value scores

\begin{tabular}{lll}
\hline & $\begin{array}{l}\text { Unstandardized } \\
\text { Regression Coefficients }\end{array}$ & t-value \\
\hline Fatalistic & 0.052 & 0.53 \\
Individualistic & 0.031 & 0.33 \\
Structuralistic & 0.094 & 1.04 \\
\hline
\end{tabular}

A stepwise regression was used to see which of the subjective estimates of class; whether occupational status, educational level of parents (mother and father separately), class status or income appeared to enter in the model. On the fatalistic dimension mothers' education was entered first with the unstandardized beta $=0.13 \quad(\mathrm{t}=2.05, \mathrm{p}<0.4) . \quad$ On the individualistic dimension none of the subjective class estimates was entered in the regression equation. On the structuralist dimension fathers' education was entered first in the equation, garnering an unstandardized beta $=0.100$ $(\mathrm{t}=1.98, \mathrm{p}=0.048)$

\section{DISCUSSION}

Subjective class estimate is usually considered to be an indicator of social status ${ }^{[30]}$ and a strong predictor of poverty attributions. In general, the representatives of higher and middle classes (and/or higher income groups) are significantly more likely to endorse individualisitc than structural poverty explanations, whereas, representatives of lower class (and/or lower income groups) are more inclined to support structural rather than individualistic beliefs ${ }^{[1,9,10,32,33]}$. Yet, the analysis showed that class was not a predictor to attribution for poverty. Perhaps the nature of the sample reporting their parents' income as mostly middle class may not appear to show the predictive power of class level. In using a step-wise regression model with the five different measures that make-up the subjective measures of class (i.e., fathers' educational level, mothers' educational level, income, occupational status, and social status), were entered in separate analysis on the three poverty dimensions (i.e. fatalistic, individualistic, and structural). Mothers' education appeared the only entered predictor on the fatalistic dimension and father's education on the structuralist attribution. In both cases, education appears to play an important role in forming the ideological imperative where fathers' education transcends a more 'political' and reasoned attribution i.e., structuralist and mothers' education a more affective transcendence i.e., fatalistic attribution.

A high structuralist attribution appeared across different class levels followed by individualistic then fatalistic. With the perspective that groups socially close to the upper social class may have an economic and emotional interest to emphasize their otherness from the poor. In an attitude that endorses individualistic attributions for poverty with expectations that they will move up in the social ladder $^{[9]}$. These conditions were not confirmed in the analyses. Perhaps, there maybe specific cognitions that poverty is deliberated through, even US middle class, samples would support the deserving poor rather than create a standard and uniform general social safety net 
system. Gilens ${ }^{[14]}$ finds that in the U.S. welfare support for the poor is better accepted than for the middle class. Feagin $^{[1]}$ on examination of a nationally representative data in the US observed that a significant and high number offered individualistic reasons (like lack of effort or loose morals), than structural ones (low wages, government inefficiency or exploitation by the rich) for poverty, while varied numbers gave fatalistic reasons (blaming poverty on bad luck, illness, fate or God). Furthermore, Feagin ${ }^{[4]}$ noted that the low-income groups tend to assign greater weight for both structural and fatalistic reasons than the affluent ones, and the responses of other groups ranged between the two extremes. Kluegel and Smith ${ }^{[10]}$ using a national survey in the 1980's found that structural beliefs resulted in compromise images of the poor (barriers to opportunity exist, but can be overcome by strenuous individual efforts), that there are specific circumstances under which the poor are seen deserving and a belief in a minimally acceptable standard of living for the poor. More recent studies in the US by Cozzarelli, Wilkinson $\&$ Tagler ${ }^{[19]}$ indicate specific conditions (i.e. cognitive) that make the middle class or upper class support a welfare system and that deserving poor who have the individual work ethic predisposition are more entitled than those who do not work or have an individual work ethic. Thus, when it comes to the attribution for poverty of deserving poor, these attributions are more structural than fatalistic. It is apparent in societies characterized by tight or close-net communities even in these societies where effort and individual "hard-work ethic" are a much-cherished social attribute in the West. It is one aspect that harnesses high social networks but not as a predominant behavioral attribute of these Eastern societies and thus, as individuals within groups, poor or rich make attributions that are external to the group as a deflection and automatic mechanism to protect the affiliate group. Studies outside the Western hemisphere as in Turkey ${ }^{[8]}, \operatorname{Iran}^{[23]}$, India ${ }^{[22,24]}$, South Africa ${ }^{[21]}$ show a predominant structuralistic attributions among different class level and an indication of a social egalitarianism among youth.

As this study presents, youth is more structuralist among high-class than those in lower classes. These results compared to those of the US ${ }^{[19]}$ and other places around the world ${ }^{[8,22,23,24]}$ say there are some universal social concurrence in the way youth in different socioeconomic class level attribute structuralist causes for poverty and an indication of an egalitarian and critical social attitudes among youth in Lebanon.

\section{REFERENCES}

1. Feagin, J. 1972. Poverty we still believe that God helps who help themselves. Psychology Today, 6: 101-129.

2. Abouchedid, K. and Nasser, R. 2001. Poverty Attitudes and their Determinants in Lebanon's Plural Society. The Journal of Economic Psychology, 22(2): 271-282.

3. Heider, F. 1958. The Psychology of Interpersonal Relations; New York: Wiley.

4. Feagin, J 1975. Subordinating poor persons: Welfare and American beliefs. Englewood Cliffs, N.J: Prentice-Hall.

5. Harper, D. 1991. The role of psychology in the analysis of poverty: some suggestions. Psychology and developing Societies, 3: 193-201.

6. Smith, K. and Stone, L. 1989. Rags, riches, and bootstraps: beliefs about causes of wealth and poverty. Sociological Quarterly, 30: 93-97.

7. Griffin, W. and Sakyi, Y. 1993. Sociodemographic and political correlates of university students' causal attributions for poverty. Psychological Reports, 73: 795-800.

8. Morcol, G. 1997. Lay explanations for poverty in Turkey and their determinants. The Journal of Social Psychology, 137(6): 728-738.

9. Hunt, M. 1996. The individual, society, or both? A comparison of Black, Latino and White beliefs about the causes of poverty. Social Forces, 75: 293-322.

10. Kluegel, J. and Smith, E. 1986. Beliefs about Inequality: Americans' View of What is and What Ought to Be; New York: Aldine De Gruyter.

11. Wagstaff, G.F. 1985. Attitudes to poverty, the protestant ethic, and political affiliation: a preliminary investigation. Social Behavior and Personality, 11(1): 45-47.

12. Furnham, A. 1982. Why are the poor with us? Explanations for poverty in Britain. Journal of Adolescence, 5: 135-147.

13. Kluegel, J. and Smith, E. 1981. Beliefs about stratification. Annual Review of Sociology, 7: 29-56.

14. Gilens, M. 1995. Racial attitudes and opposition to welfare. Journal of Politics, 57: 994-1014.

15. Carr, D. and McFadyen, R. 1998. Attitudes towards the unemployed. Human Relations, 51: 179-199.

16. Carr, S. and MacLachlan, M. 1998. Actors, observers, and attributions for Third World poverty: contrasting perspectives from Malawi and Australia. The Journal of Social Psychology, 138: 189-211. 
17. Hine, D. and Montiel, C. 1999. Poverty in developing nations: a cross-cultural attributional analysis. European Journal of Social Psychology, 29: 943-959.

18. Merton, R. 1968. Social Theory and Social Structure; New York: Free Press.

19. Cozzarelli, C., Wilkinson, A., \& Tagler, M. 2001. Attitudes toward the poor and attributions for poverty. Journal of Social Issues, 57(2): 207-227

20. Feather, N., T. 1974. Explanations of poverty in Australian and American samples: the person, society, or fate? Australian Journal of Psychology, 26: 199-216.

21. Nasser, R., Abouchedid, K. \& Khashan, H. 2002. Perceptions of the causes of poverty comparing three national groups: Lebanon, Portugal, and South Africa. Current Research in Social Psychology 8(7): 101-118.

22. Nasser, R., Singhal, S. \& Abouchedid, K. 2005. Causal Attributions for Poverty Among Indian Youth. Current Research in Social Psychology, 11(1): 1-13.

23. Hayati, D. \& Karami, E. 2005. Typology of causes of poverty: The perception of Iranian farmers. Journal of Economic Psychology 26: 884-901.

24. Singh, S. and Vasudeva, P. 1977. A factorial study of the perceived reasons for poverty. Asian Journal of Psychology and Education, 2: 51-56.

25. Shek, D. 2003. Chinese people's explanations of poverty: The perceived Causes of Poverty Scale. Research on Social Work Practice, 13: 622-640.

26. Shek, D. 2004. Beliefs about the causes of poverty in parents and adolescents experiencing economic advantage in Hong Kong. Journal of Generic Psychology, 165(3): 272-291
27. Kashima, Y., Yamaguchi, S., Kim, V., Choi, S., Gelfand, M., \& Yuki, M. 1995. Culture gender and self: A perspective from individualism-collectivism research. Journal of Personality and Social Psychology, 69: 925-937.

28. Kim,Y. 2000. Whites' explanations of Blacks' socioeconomic underachievement: individualism, structuralism, and status inconsistency, Current Research Issues in Social Psychology, 5: 1-21.

29. Kluegel, J., Singleton, R., \& Starnes, C. 1977. Subjective class identification: A multiple indicator approach. American Sociological Review, 42(4): 599-611.

30. Jackman, M. \& Jackman, R. 1973. An interpretation of the relation between objective and subjective social status. American Sociological Review, 38: 569-582.

31. Duncan, O. 1961. A socioeconomic index for all occupationsand properties and characteristics of the socioeconomic index. In Albert J. Reiss et al., Occupations and Social Status. New York: Free Press.

32. Nilson, L. 1981. Reconsidering ideological lines: Beliefs about poverty in America. The Sociological Quarterly, 22: 531-548.

33. Bullock, H. 1999. Attributions for poverty: A comparison of middle-class and welfare recipient attitudes. Journal of Applied Social Psychology, 29: 2059-82. 